\title{
An Observational Study on Clinico-Pathological Analysis of Fistula- In Ano in a Tertiary Care Hospital
}

\author{
Authors \\ Noufal TB ${ }^{1 *}$, Jothiprasad Venkatesan ${ }^{1}$, Venugopal Sarveswaran ${ }^{2}$ \\ ${ }^{1}$ Resident, ${ }^{2}$ Head of the Department
}

Department of General Surgery, Sri Ramakrishna Hospital,395, Sarojini Naidu Road, Sidhapudhur,

Coimbatore, Tamil Nadu, India - 641044

*Corresponding Author

Noufal TB

\begin{abstract}
Fistula-in ano is an abnormal communication between the anal canal or rectum and perianal skin, which causes a chronic inflammatory response. The most common cause is nearly always by a previous ano-rectal abscess. This study was intended for a clinico-pathological analysis of fistula-in ano and their diagnostic and treatment modalities based on various demographic features and associated conditions. 150 patients were selected who were diagnosed as fistula-in ano admitted and underwent surgical interventions during December 2017 to June 2019. Data related to objectives of the study were collected and analysed. Patients belonging to the age group 31-50 constituted the majority (60\%). There was male predominance with ratio of 2.4:1. Half (49.3\%) of the cases had DM and $65.3 \%$ had perianal abscess before. Most fistula were low anal (80\%). MRI Fistulogram was the most sensitive investigation. Fistulectomy was done in three-fourth (n-113, 75.3\%). There was no complication in majority and most common complication observed was wound infection (15.3\%). In majority (81.3\%) of the cases the surgical wound healed by 4 weeks. There was statistically significant difference ( $p$-0.001) in time taken to heal between diabetic and non-diabetic groups. Non-specific inflammation was the histopathology report in 146(97.3\%) cases but Tuberculosis was seen in 2 cases.
\end{abstract}

Keywords: Fistula-in ano, Fistulotomy, Fistulectomy, Perianal abscess, MRI Fistulogram.

\section{Introduction}

Anal fistula has been described virtually from the beginning of medical history. They have beleaguered patients and physicians for millennia. A thorough understanding of the anatomy and pathophysiology of the disease process is critical for optimal diagnosis and management.
The prevalence of nonspecific anal fistulae has been estimated to be 8.6 to 10 per 100000 of the population per year, with a male to female ratio of $1.8: 1^{(1)}$

Fistula-in ano is an abnormal communication between the anal canal or rectum and the perianal skin, which causes a chronic inflammatory response. 
The most common cause is nearly always by a previous ano-rectal abscess ${ }^{(2)}$. The occurrence of such abscess is mostly secondary to infection of an anal gland (crypto glandular hypothesis of Eisenhammer) ${ }^{(3)}$

Tuberculosis, lymphogranuloma inguinale, inflammatory bowel disease like Crohn's or ulcerative proctocolitis can also lead to development of anal fistula. Fistulae have been reported following external injury or probing an abscess or low anal fistula ${ }^{(4)}$. A fistula may develop in chronic anal fissure. A colloid carcinoma of the rectum can manifest itself through an anal fistula ${ }^{(5)}$. Occasionally ingested foreign body, such as fish or chicken bones may penetrate the rectum. Impalement injury after falling astride a sharp object or as a result of a road traffic accident may result in a high ano-rectal fistula.

According to Park classification ${ }^{(6)}$ the anal fistula can be classified in to four types: Intersphincteric (70\%), Transphincteric (25\%), Suprasphincteric (5\%), Extrasphincteric $(1 \%)$.

According to Standard (Milligan Morgan, Goligher) classificaion fistula is of five types: Subcutaneous (commonest), Low anal (common), Submucous, High anal, Pelvi rectal.

The chief complaint is either intermittent or constant drainage or discharge. There is usually a history of previous pain, swelling and recurrent abscess that ruptured spontaneously or was surgically drained. There may be pink or red elevation exuding pus, or it may have healed.

In Crohn's disease or tuberculosis, the margins may be violaceous and the discharge is watery. ${ }^{(7)}$

Physical examination findings remain the main stay of diagnosis. The examiner should observe the entire perineum, looking for an external opening that appears as an open sinus or elevation of granulation tissue. Spontaneous discharge via the external opening may apparent or expressible upon digital rectal examination. Digital rectal examination may reveal a fibrous tract or cord beneath the skin, it also helps to delineate any further acute inflammation that is not yet drained.
Lateral or posterior induration may suggest deep posterior anal or ischiorectal extension ${ }^{(3)}$.

Commonly done investigations in fistula-in ano are sigmoidoscopy, colonoscopy, fistulography, endo anal/ transrectal ultrasound, MRI fistulogram, CT Scan, Barium enema or small bowel series, fistuloscopy. But thorough clinical examination is most important ${ }^{(8)}$.

The main objective of surgical treatment of an anal fistula is to eradicate the disease without disturbing the anal continence. The different surgical treatment modalities $^{(9)}$ are Fistulectomy, Fistulotomy, Advancement flaps, Gluing of the fistula tract, Anal fistula plug (AFP), LIFT technique(ligation of intersphincteric fistula tract), VAAFT procedure (video assisted anal fistula tract ligation), Seton Technique.

The purpose of this study is to evaluate the usefulness of clinical examination combined with imaging in managing fistula-in ano, to discuss various risk factors or associations and to encourage the community to avoid the occurrence of disease. To health educate the patients regarding factors like diet, constipation to avoid recurrence of disease after surgery and to recommend the surgeons to combine fistulectomy along with abscess drainage as a single stage procedure to avoid later development of fistula. And finally because of the scarcity of this kind of study in our region of the country.

\section{Material and Methods}

This was a prospective observational study conducted at Department of general surgery during December 2017 to June 2019.

150 patients were selected who were diagnosed as fistula-in ano admitted and underwent surgical interventions.

\section{Inclusion Criteria}

All patients who are clinically diagnosed as fistula in ano in all ages and both sex who are subjected to relevant investigations and will undergo surgery would be included.

\section{Exclusion Criteria}

- Fistula in ano due to perianal injuries 
- Congenital fistulas

- Cases unfit and refused for surgery

\section{Methodology}

- Patients will be examined clinically after taking a detailed history including all risk factors and associated conditions.

- Then they will be investigated with routine laboratory tests, trans rectal ultrasound or MRI Fistulogram.

- All patients will undergo various surgical treatments accordingly.

- The fistulous tract of those patients who underwent fistulectomy will be subjected to HPE.

- Patients will be followed up for 3 months for effectiveness of treatment.

- Finally all parameters will be analyzed by statistical methods.

\section{Statistical Methods}

Data will be entered in Ms Excel and be exported to SPPS 16 and Sigma Stat 3.5 version for statistical analysis.

Figures are presented in numbers and percentages. Appropriate graphs have been drawn where necessary. Multiple response table was drawn to address multiple symptoms in each case. Association between relevant categorical variables were assessed using Chi Square test. An independent $t$ test was performed to compare two means. A cumulative survival probability was calculated for recurrence of fistula by Kaplan Meier method. A p value less than 0.05 is considered statistically significant.

\section{Observation and Results}

A diagnosis of fistula in ano was made in patients aged $42.1 \pm 10.9$ years ranging from 17 to 67 years. Close to half $(46.0 \%)$ of the patients were aged 40 and below. Patients belonging to the age group 3150 constituted the majority $(60.0 \%)$ (Figure.1). Seven $(4.7 \%)$ patients were aged more than 60 , and $2(1.3 \%)$ were aged less than 20 years of age.

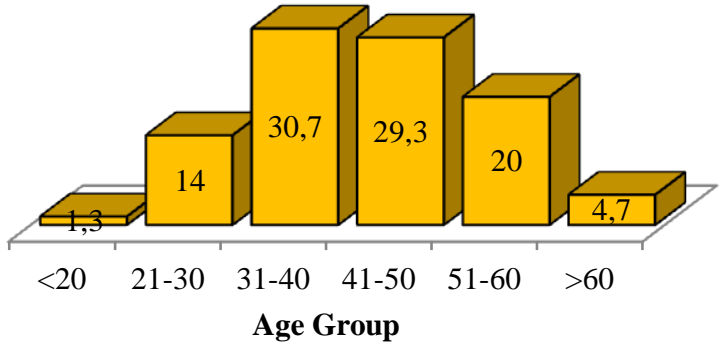

Figure.1: Age Distribution of Fistula-in Ano Patients

More than two-thirds (70.7\%) of the patients were male and 44(29.3\%) were female (Figure. 2). The distribution of age across gender was even and was not statistically significantly different ( $\mathrm{p}-0.402)$ (Figure. 2).

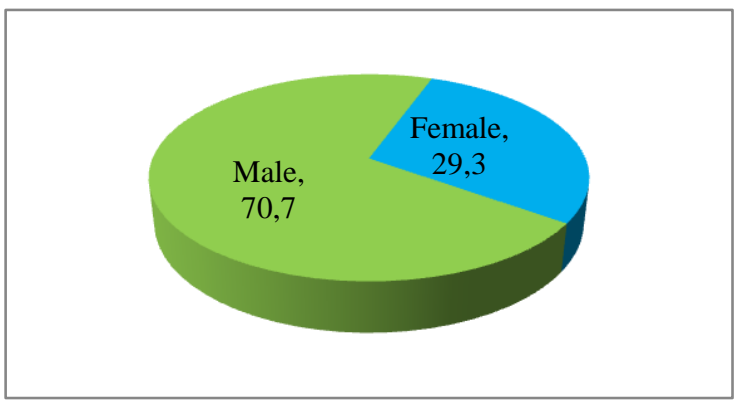

Figure 2: Gender Distribution of Fistula in Ano Patients

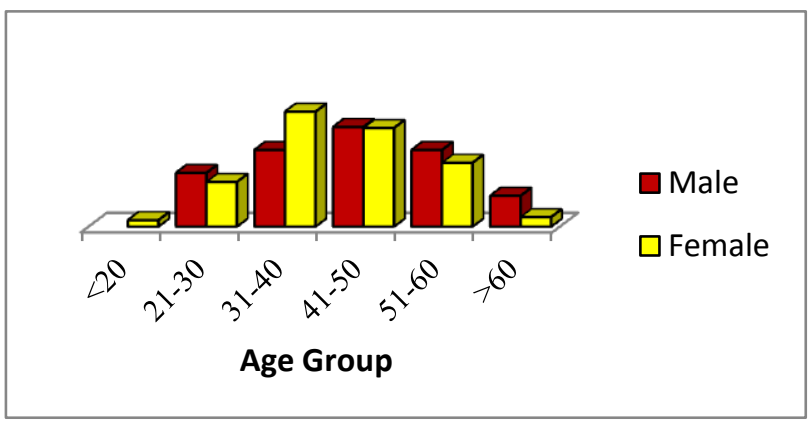

Figure 3: Age-Gender Distribution of Fistual in Ano Patients

Patients in the study belonged to middle class in 104 (69.3\%) instances. A meagre (8.7\%, n-13) belonged to high SES while 33(22.0\%) were classified as 'poor'. 
Half $(49.3 \%)$ of the cases reportedly had history of diabetes mellitus. Majority (65.3\%) had had perianal abscess before. Three $(2.0 \%)$ patients were found to have had IBD (Crohn's or ulcerative colitis). There was one $(0.7 \%)$ instance of history or tuberculosis and one carcinoma of the rectum.

The minimum number of symptoms was two at presentation. Majority (66.7, n-100) of the patients presented with three symptoms. One fourth $(28.0 \%)$ of patients presented with two symptoms. Eight $(5.3 \%)$ patients presented with 4 symptoms. The following table (table.1) provides the information on the multiple symptoms the patients presented with. All (100.0\%) patients presented with discharge invariably, followed by external opening in $102(68.0 \%)$ patients. More than half $(53.3 \%)$ of the cases presented with pain and 60(40.0\%) complained of swelling. Bleeding per rectum was seen in 7(4.7\%) patients (figure.4).

Table 1: Presentation of Multiple Symptoms among Fistula-in ano Cases in the Study

\begin{tabular}{|l|c|c|c|}
\hline Presentation & $\mathrm{N}$ & $\begin{array}{c}\text { Percent of } \\
\text { Symptoms }\end{array}$ & $\begin{array}{c}\text { Percent } \\
\text { of Cases }\end{array}$ \\
\hline Pain & 80 & $19.2 \%$ & $53.3 \%$ \\
\hline Discharge & 150 & $36.1 \%$ & $100.0 \%$ \\
\hline Swelling & 60 & $14.4 \%$ & $40.0 \%$ \\
\hline Pruritis & 17 & $4.1 \%$ & $11.3 \%$ \\
\hline External opening & 102 & $24.5 \%$ & $68.0 \%$ \\
\hline Bleeding per rectum & 7 & $1.7 \%$ & $4.7 \%$ \\
\hline Total & 416 & $100.0 \%$ & $277.3 \%$ \\
\hline
\end{tabular}

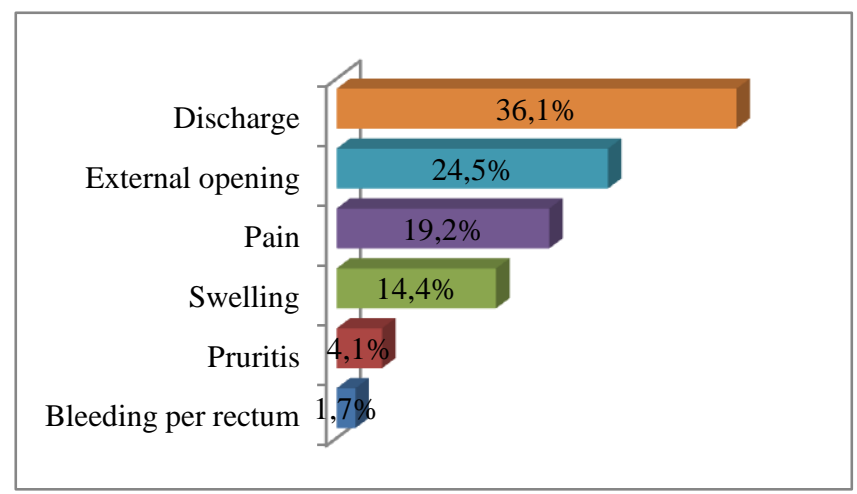

Figure 4: Presentation of Symptoms among Fistula-in ano Cases

The distribution of symptoms was not statistically significantly different ( $\mathrm{p}-0.546)$ between gender (Figure.5). Similarly, presentation of symptoms was uniform across the socio-economic status categories and was not statistically significantly (p-0.913).

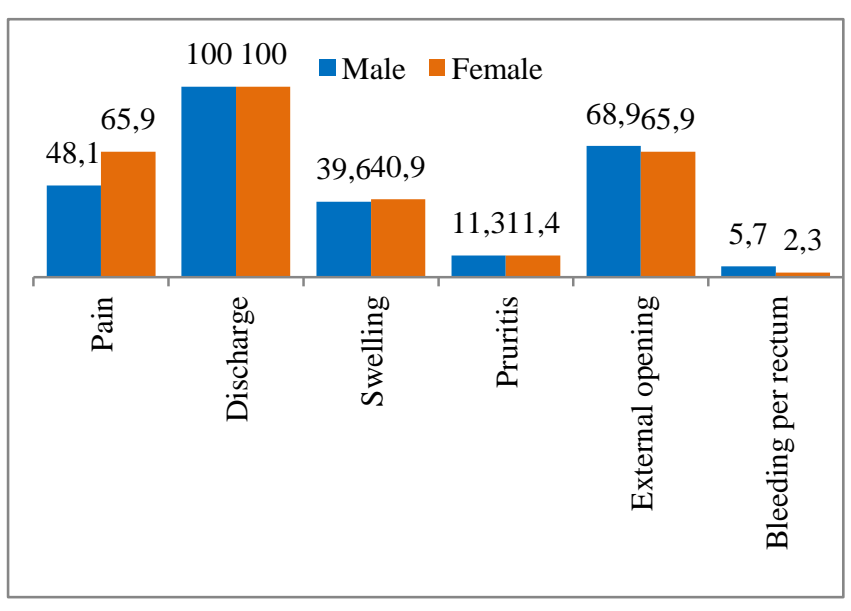

Figure 5: Presentation of Symptoms by Gender in Fistula-in ano Cases

One-fourth $(26.7 \%, \mathrm{n}-40)$ patients had perianal abscess present. Fissure was seen in 21 (14.0\%) cases followed by hemorrhoids in $9(6.0 \%)$ and $\mathrm{BPH}$ in $7(4.7 \%)$ cases. Presentation of associated perianal abscess was not statistically significantly (p-1.0) associated with pre-existing diabetes mellitus. Both groups (with and without associated perianal abscess) had equal proportion (close to 50.0\%) of patients with history of DM.

Of the 102 cases that had external opening, majority $(83.3 \%)$ had one, $15(14.7 \%)$ had two openings. Two $(2.0 \%)$ cases had multiple $(>2)$ openings. The position of the external opening was posterior in most $(65.7 \%)$ of the cases. One-tenth $(10.8 \%)$ of the cases had external opening in the lateral position and $23(22.5 \%)$ in the anterior position.

MR Fistulogram was the choice of imaging in 95(63.3\%) instances (Figure.6). Rest (36.7\%, n-55) of the cases used the mode of trans-rectal ultrasound.

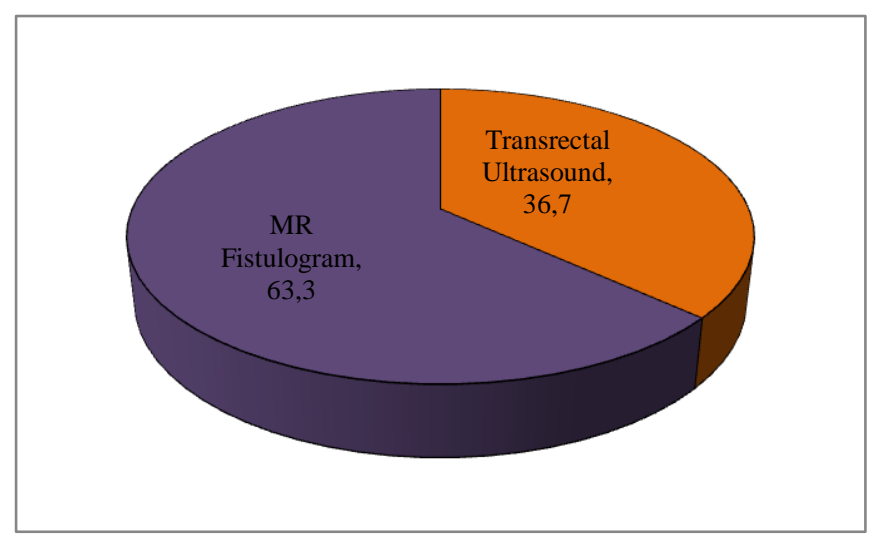

Figure 6: Imaging Modality used in Fistula-in ano Cases 
By standard classification the fistula in ano were low anal in $120(80.0 \%)$ cases, followed by subcutaneous $(9.3 \%)$ (Figrure.7).

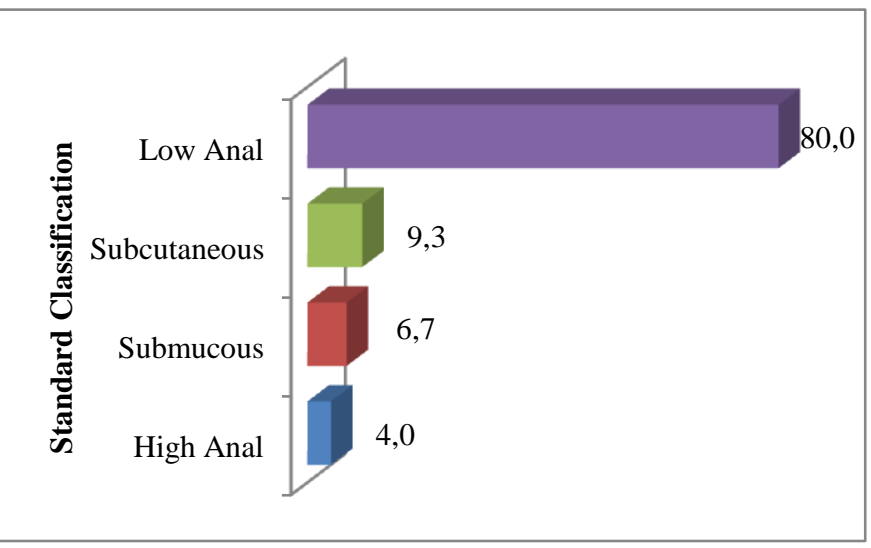

Figure.7: Standard Classification of Fistula-in ano

Fistulectomy was required in three-fourth $(75.3 \%$, $\mathrm{n}-113)$ of the cases. Seton placement was done in $10 \%$ of the cases followed by fistulotomy in 14 $(9.3 \%)$ cases. Five cases needed VAAFT and 3 (2.0\%) needed LIFT (figure. 8).

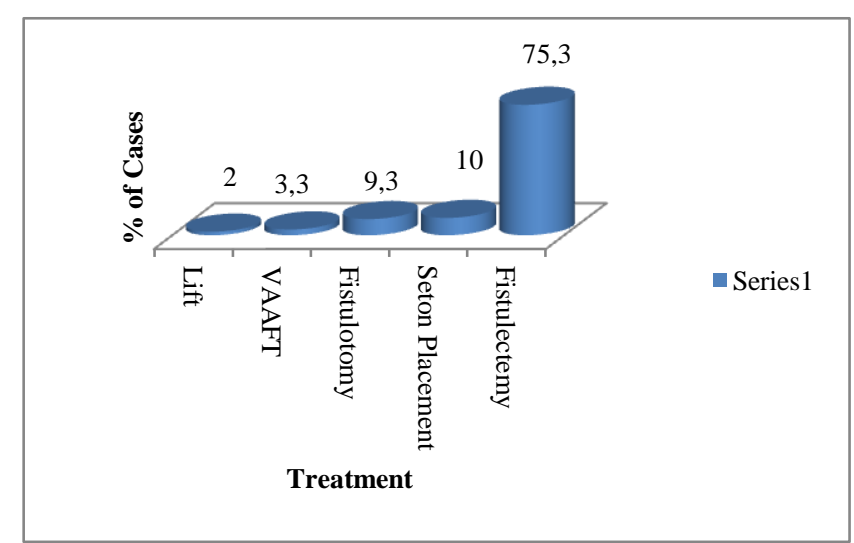

Figure 8: Treatment Opted for Fistula-in ano Patients

There was no complication in majority $(82.7 \%)$ of the cases. Postoperative wound infection was recorded in 23(15.3\%) cases (Figure. 9) and postoperative faecal incontinence in $3(2.0 \%)$ cases.

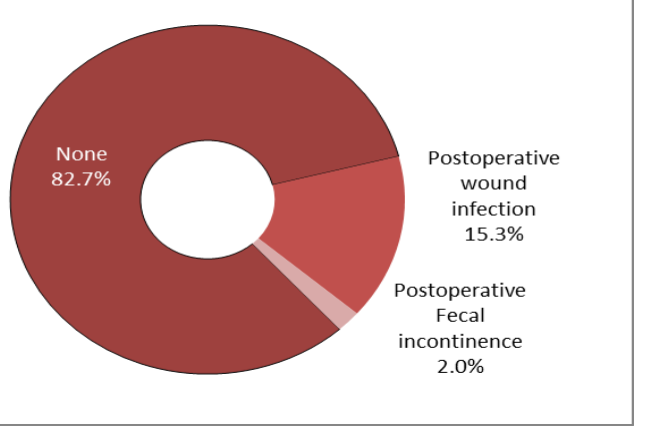

Figure 9: Complications following Treatment for Fistula-in ano

Early post op healing ( $<=3$ weeks) was seen in $43.3 \%$ (n-65) of the cases. In majority $(81.3 \%)$ of the cases the surgical wound healed by 4 weeks postoperatively. More than one third $(38.0 \%)$ of the wounds healed on the $4^{\text {th }}$ postoperative week. Fifteen $(10.0 \%)$ cases took 6 weeks to heal (figure. $10)$.

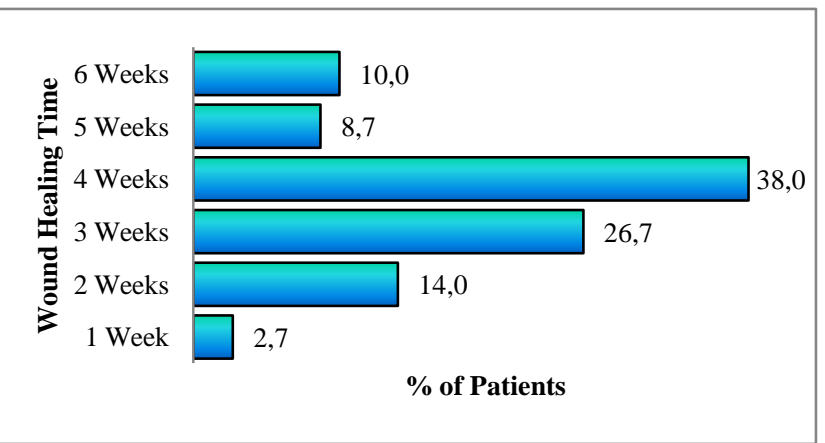

Figure 10: Wound Healing Time among Fistula in Ano Treated Patients

There was no statistically significant difference between gender ( $\mathrm{p}-0.170)$ or socio-economic status (p-0.492) in terms of wound healing.

Wound healing time was compared between patients with and without history of DM (Figure.11) There was a statistically significant difference ( $p$ 0.001) in time taken to wound healing between diabetic and non-diabetic groups. The trend of healing was similar between the two group, though the percentage healing was lower among the diabetic patients. All the cases that healed after 5 weeks were diabetic.

When wound healing time was compared between presence of associated perianal abscess (n-40), the beginning of healing seemed to be delayed among 
those with the condition (Figure.12). However, the numbers of people healing in the following weeks were similar to those who did not have perianal abscess and the difference was not statistically significant ( $\mathrm{p}-0.117)$

The Wound healing time when compared between the standard classifications of fistula, it was observed that there was no statistically significant difference (p-0.844) (figure.13).

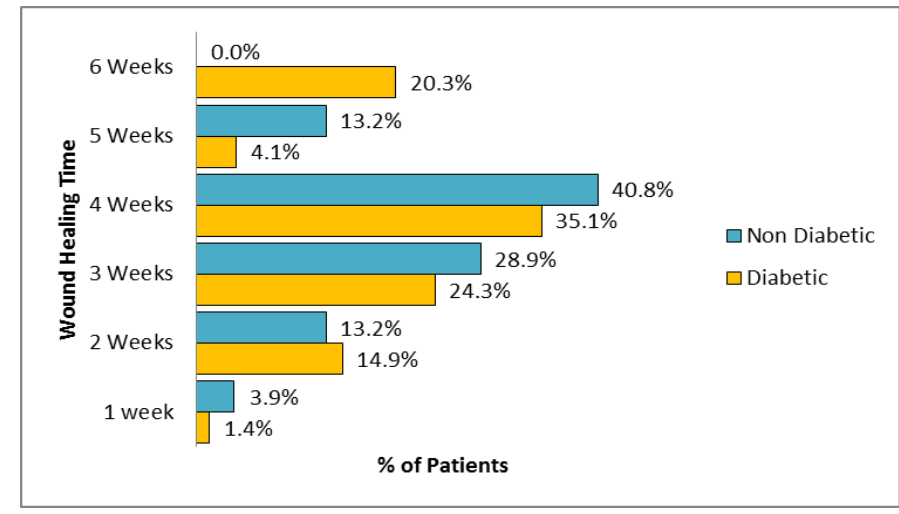

Figure.11: Wound Healing and Diabetes Mellitus among Fistula in Ano Patients

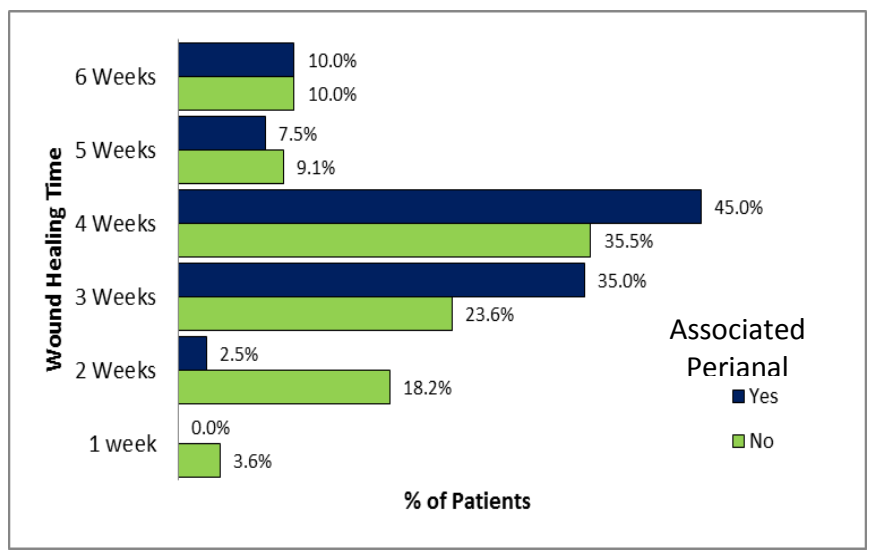

Figure 12: Wound Healing Time and Associated Perianal Abscess

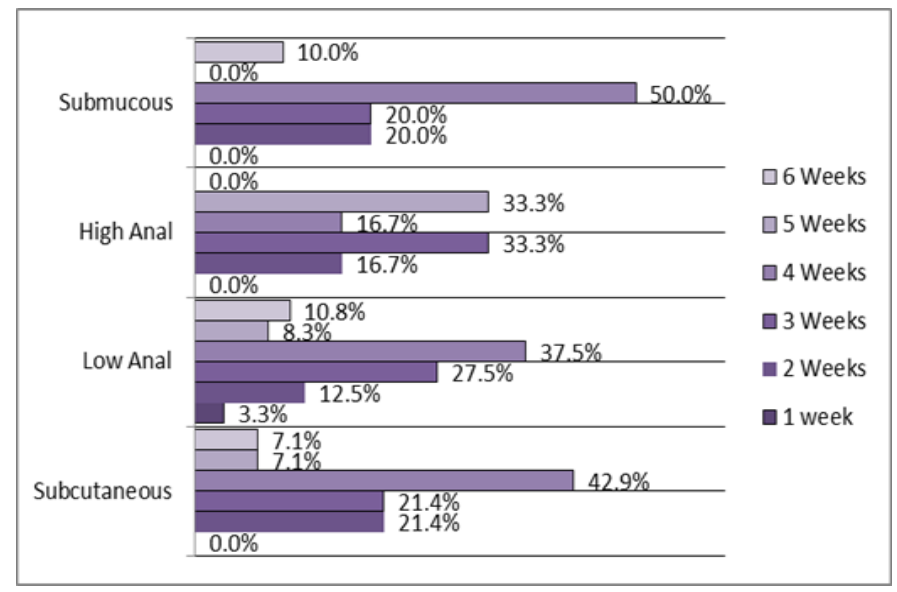

Figure 13: Wound Healing Time and Standard Classification of Fistula-in ano Patients
The wound healing time when compared with treatment option, it was observed that there was no statistically significant difference (p-0.624) (figure.14).

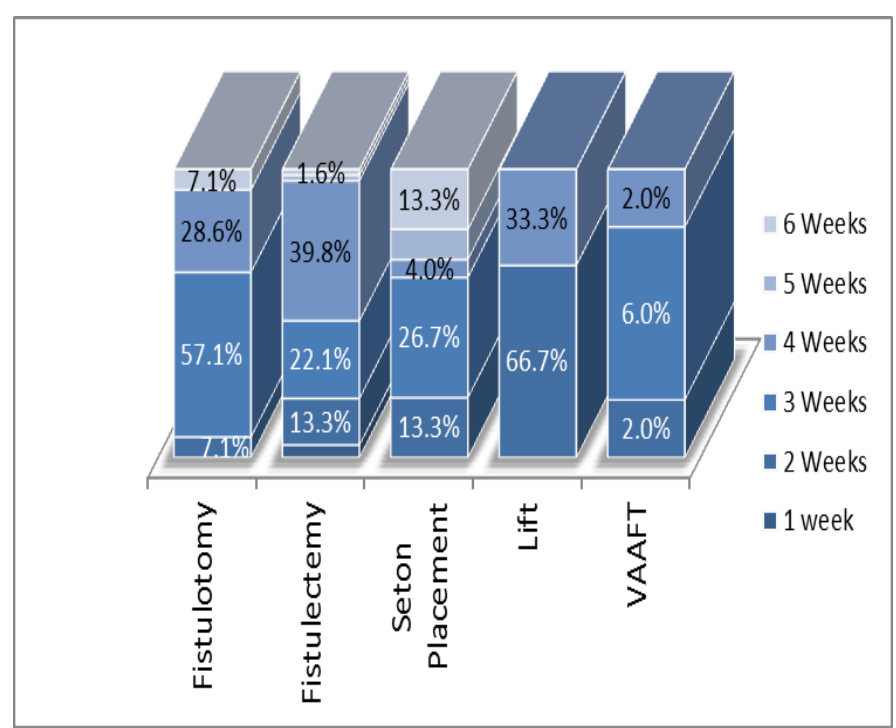

Figure 14: Wound Healing Time and Type of Treatment for Fistula-in ano Patients

Reports from histopathology laboratory suggested non-specific inflammation in 146 (97.3\%) cases. Tuberculosis was seen in 2 cases, while SCC and Crohn's in one case each.

All cases were followed up for 3 months postoperatively. Recurrence of Fistula in ano was seen in $6(4.0 \%)$ cases during this time. The recurrent cases were aged on an average $41.5 \pm 11.3$ year and $83.3 \%(n-5)$ male. They belonged to the middle and lower socio economic status; $66.7 \%$ (n-4) had history of diabetes and all of them had history of perianal abscess. Majority (83.3\%, n-5) were low anal fistula and one was submucous. However, recurrence of fistula in ano was not associated with age ( $p-0.896)$, gender ( $p-0.487)$, history of diabetes (p-0.681), socio economic status ( $\mathrm{p}-0.671)$, history of perianal abscess (p-0.069) or their preoperative standard classification (p- 0.619).

The recurrence was observed on an average in $78.1 \pm 7.3$ ranging from 67 to 86 days. The mean survival time from recurrence post fistula in ano treatment was 91 (95\% CI:90.5, 91.4) days in this study. The survival probability begins at 1.0 till the first recurrence occurs in the $67^{\text {th }}$ day (Figure.15). 
The survival probability drops to 0.993 on the $67^{\text {th }}$ day and later to 0.987 as and when the next event of recurrence happened in the $72^{\text {nd }}$ day. The cumulative survival probability (Figure. 15) from recurrence is 0.96 at the end of the postoperative $3^{\text {rd }}$ month.

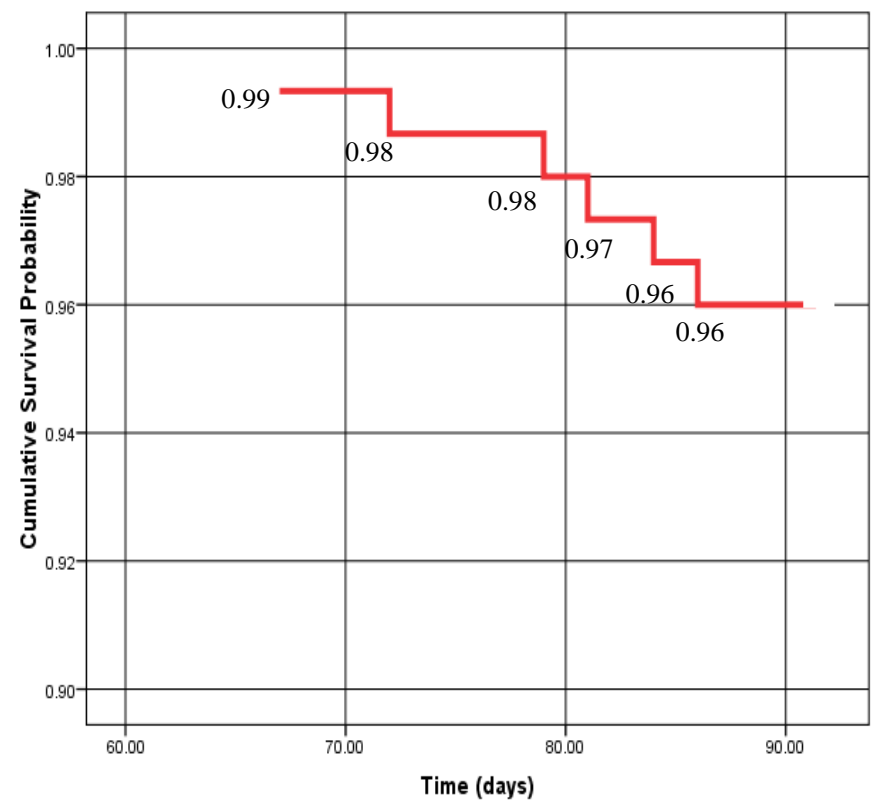

Figure 15: Cumulative Survival Probability from Recurrence of Fistual in Ano Post Treatment

\section{Discussion}

We have studied 150 consecutive patients who were clinically diagnosed as fistula-in ano. Detailed analysis has been done and has been compared with statistics available from Indian authors and other authors of the world.

There is a more male dominance in reported series [10]. Kim JW et al. reported the male: female of 4.6:1 in Korea [11]. Most patients with an anal fistula present in the third or fourth decade of life ${ }^{[12]}$ and anal fistulas were uncommon after the age of 60 years. In our study also there is a male predominance with a ratio of $2.4: 1$.

Most of the patients in our study present between the 31 - 40 years and only 7 were in the age group of more than 60 years shows that our study almost matches with their study in male: female ratio and age incidence.

As per the study done by Marks and Ritchie ${ }^{[13]}$ in a series of 793 patients the fistulas were divided as low anal $(54 \%)$, sub cutaneous $(16 \%)$, sub mucous
(21\%), high anal (3\%) and multiple or unclassified $(6 \%)$.

In our study, low anal in $80 \%$ and High anal in $4 \%$. This disparity may be explained by the fact that our study constituted a very small study group (150 patients).

In a study done by Marks and Ritchie ${ }^{[13]}$, the site of internal opening is anterior, posterior and lateral. In our study anterior in $22.5 \%$, posterior in $67.7 \%$ and lateral in $10.8 \%$, almost matches with the above said study.

A patient with a fistula-in-ano often recounts a history of an abscess, drained either surgically or spontaneously. Patients may complain of drainage, pain with defecation, bleeding ${ }^{[13] \text {. }}$

Vasilevsky and Gordon ${ }^{[14]}$ recorded a history of discharge, anal pain, a recurrent perianal swelling, bleeding, and pruritis. Associated fissure in ano was recorded in their patients. Many patients also have haemorrhoids.

In our study, a history of discharge was in $100 \%$, anal pain in $53.3 \%$, perianal swelling in $40 \%$, bleeding in $4.7 \%$ and pruritis in $11.3 \%$ of patients. Associated fissure in ano was recorded in $14 \%$ of patients and haemorrhoids in $6 \%$ of patients, almost nearer to their study.

Parks and Stitz ${ }^{[15]}$ demonstrated that hospital stay and healing times was much longer in patients treated for submucosal and high anal as compared with those treated for low anal and subcutaneous fistula. In our study also $60 \%$ of submucous and $56 \%$ of the high anal fistula patients took more than 4 weeks to heal and $80.8 \%$ of low anal and $85.7 \%$ of subcutaneous fistula wounds healed within 4 weeks matches with their study.

In a study buMalouf, et al. in St. Marks Hospital, UK, the proportion of the tuberculous pathology was too low owing to the lesser incidence of TB in European countries ${ }^{(16)}$.

In our study of 150 cases, 2 cases (2.7\%) had histopathological evidence of tuberculosis (table 2). 
Table 2: Comparison of tuberculous etiology

\begin{tabular}{|l|c|}
\hline Study & TB \\
\hline Bokhari, et al. [17] & $11 \%$ \\
\hline Wijekoon, et al. [18] & $7 \%$ \\
\hline Malouf, et al. [16] & $1 \%$ \\
\hline Present study & $2.7 \%$ \\
\hline
\end{tabular}

In the present study, we found $4 \%$ ( 6 cases) of cases had recurrence and most of them were males (table 3)

Table 3: Comparison of recurrence

\begin{tabular}{|l|c|}
\hline Study & Recurrence \\
\hline Sangwan, et al. [19] & $6.5 \%$ \\
\hline Malouf, et al. [20] & $4 \%$ \\
\hline Present study & $4 \%$ \\
\hline
\end{tabular}

True fecal incontinence is variable, ranging from nil to $26 \%$. In our study 3 cases had transient incontinence for fluids and flatus for about 2 weeks matches with the most of the case reports.

The morbidity is much low and the present record for more conservative methods for treating extrasphincteric fistulas is more encouraging and holds real promise for a more successful outcome for fistula surgery in the future.

\section{Conclusion}

We conclude that the previously burst opened or surgically drained perianal abscess is the main aetiological factor for fistula-in ano. Operative morbidity is usually low. There is a male preference for the disease and the fistulectomy remains the commonest procedure in our study series even with advent of newer techniques probably to remove the diseased part at one stage operation.

The post-operative complications are usually mild in nature and are minimal but carries a significant risk of recurrence. Factors vary ranging from type of fistula to etiology of the disease, apart from inadequate excision of branching tracts, failure to visualize the entire tract and internal opening. Preoperative MRI may help to detect the type of fistula, localize the internal opening and should be performed in all complex fistulas. Histopathological examination assumes paramount significance to suspect and anticipate recurrence. Regular follow- up in patients with fistula after treatment is required to monitor recurrence.

Health educating the community regarding the risk factors will helps to prevent the occurance of the disease and by proper discharge advice and follow up schedule the reccurence can also be avoided.

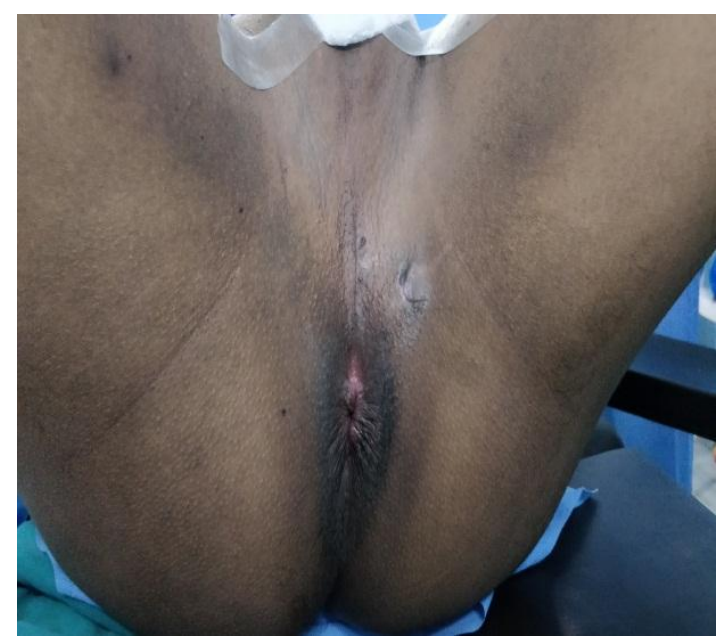

Figure 16. Fistula-in ano

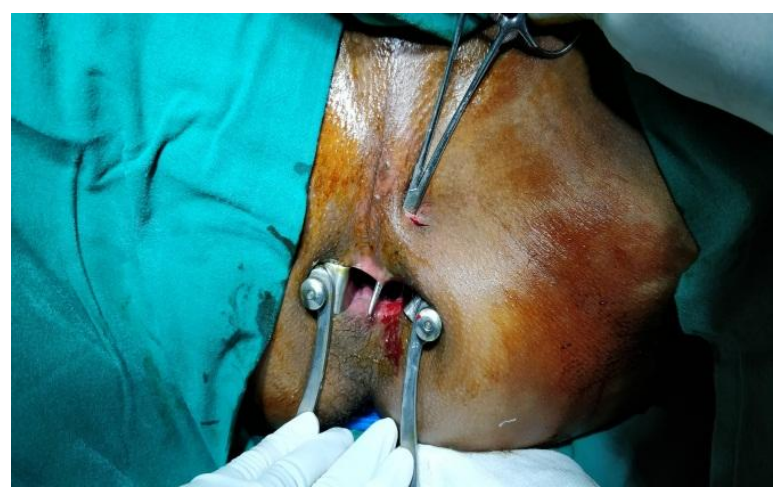

Figure.17: Probe through fistula tract

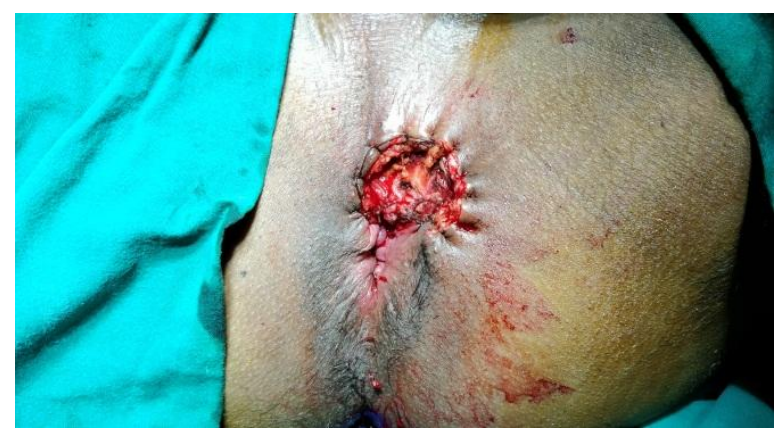

Figure 18: Post fistulectomy wound

\section{References}

1. Deeba S, Aziz O, Sains PS, Darzi A. Fistulain-ano: advances in treatment. The American Journal of Surgery. 2008 Jul 1;196(1):95-9. 
2. Lawrence W. Current surgical diagnosis \& treatment. Appleton \& Lange; 1994.

3. Adams D, Kovalcik PJ. Fistula in ano. Surgery, gynecology \& obstetrics. 1981 Nov; 153(5):731-2.

4. Gupta PJ. Point of Technique-Radio frequency fistulotomy: A better tool than the conventional techniques in anal fistula.

5. Isbister WH. Fistula in ano: a surgical audit. International journal of colorectal disease. 1995 Apr 1;10(2):94-6.

6. Parks AG, Stitz RW; The treatment of high fistulainano. Disease of the Colon and Rectum, 1976; 19: 487-499.

7. Panda UN; Current Medical Diagnosis and Treatment. Jaypee Brothers Publishers, 2002.

8. Vasilevsky CA, Gordon PH. The incidence of recurrent abscesses or fistula-in-ano following anorectal suppuration. Diseases of the Colon \& Rectum. 1984 Feb 1;27(2):12630.

9. Tadataka Yamada; Textbook of Gastroenterology. John Wiley \& Sons, 2011. 13.

10. Sainio P. Fistula-in-ano in a defined population. Incidence and epidemiological aspects. In Annales chirurgiae et gynaecologiae 1984 (Vol. 73, No. 4, pp. 219-224).

11. Kim JW, Kwon SW, Son SW, Ahn DH, Lee KP; Comparative Review of Perianal Sinus \& Fistula in Ano. J Korean Soc Coloproctol., 2000; 16(1):7-11.

12. Owen HA, Buchanan GN, Schizas A, Cohen R, Williams AB. Quality of life with anal fistula. The Annals of The Royal College of Surgeons of England. 2016 May;98(5):334-8.

13. Marks CG, Ritchie JK; Anal fistulas at St Mark's Hospital. Br J Surg., 1977; 64(2): 8491.

14. Vasilevsky CA, Gordon PH; The incidence of recurrent abscesses or fistula-in-ano following anorectal suppuration. Dis Colon Rectum, 1984; 27(2):126-130.
15. Parks AG, Stitz RW. The treatment of high fistula-in-ano. Dis Colon Rectum. 1976; 19(6):487-99.

16. A. J. Malouf, G. N. Buchanan, E. A. Carapeti, S. Rao, R. J Guy, E. Westcott, J. P. S. Thomson, C. R. G. Cohen. A prospective audit of fistula-in-ano at St. Mark's hospital. Blackwell Science Ltd. Colorectal Disease, 2002; 4: 13-19.

17. Bokhari I, Shah SS, Inamullah, Mehmood Z, Ali SU, Khan. A Tubercular fistula-in-ano. J Coll Physicians Surg Pak., 2008; 18(7): 4013.

18. Wijekoon NS, Samarasekera DN. The value of routine histopathological analysis in patients with fistula in-ano. Colorectal Dis., 2010; 12(2): 94-6.

19. Goligher JC. Surgical anatomy and physiology of the colon, rectum, and anus. In: Goligher JC, editor. Surgery of the anus, rectum, and colon. 5th ed. London: BalliereTindall; 1984.

20. Dalley AF. The riddle of the sphincters, the morphophysiology of the anorectal mechanism reviewed. Am Surg. 1987; 53:298-306. 